\title{
Demonstration of Elemental Partitioning During Austenite Formation in Low-Carbon Aluminium Alloyed Steel
}

\author{
Y. Palizdar ${ }^{\text {a }}$, D. San Martin ${ }^{\text {b }}$, A. P. Brown ${ }^{\text {a }}$, M Ward ${ }^{\text {a }}$, R. C. Cochrane ${ }^{\text {a }}$ R. Brydson ${ }^{\text {a }}$, and A. J. Scott ${ }^{\text {a }}$ \\ anstitute for Materials Research, SPEME, University of Leeds, Leeds LS2 9JT UK
}

${ }^{\text {b} M A T E R A L I A ~ g r o u p, ~ D e p a r t m e n t ~ o f ~ P h y s i c a l ~ M e t a l l u r g y, ~(C E N I M-C S I C), ~ C e n t r o ~ N a c i o n a l ~ d e ~}$ Investigaciones Metalúrgicas Av. Gregorio del Amo 8, 20040 Madrid, Spain.

This work investigates the influence of aluminium, in solid solution, on austenite formation in a lowcarbon aluminium alloyed $(0.48$ wt. \%) steel during continuous heating. A thin section across an untransformed ferrite and austenite interface was prepared for transmission electron microscopy by focused ion beam milling. Microstructural characterization using imaging and elemental analysis demonstrates that aluminium partitions from austenite to ferrite during very slow heating conditions, stabilizing this latter phase and shifting the final transformation temperature for austenite formation $\left(\mathrm{Ac}_{3}\right)$.

Keywords: Low-carbon steel, Austenitization, FIB-TEM.

\section{Introduction}

Austenite formation is an important and much studied process in steel research, being intensively investigated in low and medium carbon steels.. In ferritic-pearlitic steels this process can be split into two: nucleation of austenite in pearlitic colonies with rapid growth of austenite consuming pearlite followed by the slower growth of austenite consuming ferrite [1-6]. Studies of the effect of substitutional elements such as manganese and chromium on austenite formation have shown that they slow down the transformation when partitioning of the elements occurs during austenitization [2, 3]. There has been little research concerning the effect of aluminium as a substitutional element in steel in amounts higher than 0.1 wt. \% despite a general awareness that $\mathrm{Al}$ is a ferrite stabilizer and tends to expand the ferrite + austenite phase field of the equilibrium phase diagram. This could be due to technological concerns over the production of high $\mathrm{Al}$-content steels. Commercial interest has emerged recently with studies on $\mathrm{Al}$ additions, of the order of $0.5-2$ wt. $\%$, to low carbon high strength strip steels to produce a multi-phase 
microstructure containing retained austenite for cold forming applications [7-10]. There is still limited knowledge regarding the role of $\mathrm{Al}$ as a solute in such steels; work is required to understand its influence on phase transformations and microstructures. This study investigates the influence of $\mathrm{Al}$ in solid solution on austenite formation during continuous heating.

\section{Experimental procedure}

Steels with a base composition of: 0.02 wt.\% C, 1.41 wt.\% Mn, 0.001 wt.\% $\mathrm{N}$ and different concentrations of aluminium: $0.02 \mathrm{wt} . \%$ (Steel E) and $0.48 \mathrm{wt} \%$ (Steel F) were produced. The initial microstructure of the steel is ferritic with some small pearlite islands. For more details regarding the processing, microstructure and sample preparation readers are referred to other publications [11-14]. A high resolution dilatometer (Adamel Lhomargy DT1000) was employed to determine the critical transformation temperatures for the end of the austenite formation process $\left(\mathrm{Ac}_{3}\right)$; samples of $12 \mathrm{~mm}$ in length and $2 \mathrm{~mm}$ in diameter were continuously heated at $0.05{ }^{\circ} \mathrm{C} / \mathrm{s}$ and $7{ }^{\circ} \mathrm{C} / \mathrm{s}$.

\section{Results and discussion}

Table 1 displays the $\mathrm{Ac}_{3}$ temperature determined from dilatometry plots, for the two heating conditions. The addition of 0.48 wt $\% \mathrm{Al}$ increases $\mathrm{Ac}_{3}$ from $~ 910$ to $987-1025{ }^{\circ} \mathrm{C}$, consistent with $\mathrm{Al}$ acting as a ferrite stabilizer and expanding the ferrite + austenite phase field. The Al-alloyed steel (F), has an $\mathrm{Ac}_{3}$ that is very sensitive to the applied heating rate, in contrast to steel E. For steel F, the $\mathrm{Ac}_{3}$ increases (from 987 to $1026{ }^{\circ} \mathrm{C}$ ) with a slower heating rate. Previous work on the effect of heating rate on $\mathrm{Ac}_{3}$ in low and medium steels without $\mathrm{Al}$ show the opposite, a faster heating rate gives a higher $\mathrm{Ac}_{3}$ since a faster heating rate takes the steel from equilibrium conditions $[1,15]$. The most likely interpretation for the observation here is the diffusion or partitioning of $\mathrm{Al}$ to the untransformed ferrite grains, delaying their transformation to higher temperatures. Thus, at temperatures close to $\mathrm{Ac}_{3}$ a greater concentration of $\mathrm{Al}$ is expected in the untransformed ferrite grains of an Al-rich steel (steel F); this would be most prominent at a slow heating rate (such as $0.05{ }^{\circ} \mathrm{C} / \mathrm{s}$ ) since this allows $\mathrm{Al}$ time to diffuse and partition. We have investigated $\mathrm{Al}$ levels (by energy dispersive X-ray spectroscopy [EDX] in TEM) in an untransformed ferrite grain and a former austenite grain of the partially transformed steel $\mathrm{F}$ (details below). It is well known that during austenitization heat treatment, partitioning of alloying elements may occur, that the extent is dependant on the relative solubilities in austenite and ferrite and that this phenomenon can affect the transformation kinetics in steel $[2,3]$. It is well documented that annealing in the ferrite-austentite phase region can produce Mn partitioning [16, 17] however, there is little literature concerning partitioning of Al during the austenitization process. Koo et. al. [18] have shown that Al partitions under certain heating conditions during intercritical annealing (ferrite/austenite region) of steels alloyed with 1 wt.\% $\mathrm{Al}$ and 
Amirthalingam et.al.[19] have shown higher concentrations of $\mathrm{Al}$ in ferrite grains in welded, high silicon and high aluminium TRIP steels.

To study the austenite/ferrite interface in the $\mathrm{Al}$ added steel (F), a specimen ( $2 \mathrm{~cm}$ cube) was heated continuously at $0.05{ }^{\circ} \mathrm{C} / \mathrm{s}$ up to $970{ }^{\circ} \mathrm{C}$ and water quenched to room temperature. Standard metallographic procedures were carried out to reveal the microstructure (Fig. 1a). To ensure a TEM thin foil sample containing an appropriate untransformed ferrite and former austentite boundary was produced sitespecific focused ion beam (FIB) preparation was utilized. A TEM thin foil (thickness $\sim 60 \mathrm{~nm}$, determined by the ratio of inelastic to elastically scattered electrons in the electron energy loss spectrum) was prepared using a FEI NOVA200 dual beam FIB/SEM (Fig. 1b). A $30 \mathrm{keV} \mathrm{Ga} \mathrm{ion} \mathrm{beam} \mathrm{was} \mathrm{used,} \mathrm{and} \mathrm{for}$ final thinning the beam current was varied from 500 to 50 pA. An FEI CM200 TEM, fitted with a Gatan imaging filter and an Oxford Instruments EDX spectrometer was used to examine the FIB section.. EDX spectra were taken in TEM mode with a spot size of $\sim 6 \mathrm{~nm}$ diameter (we estimate this increases to $10 \mathrm{~nm}$ after beam broadening by the specimen) and were quantified using Oxford Instruments' ISIS software (including an appropriate absorption).

The heat treated steel contains a mixture of large ferrite grains (approximately $10 \%$ of the bulk) and relatively fine ferrite grains (approximately $90 \%$ of the bulk; Fig. 1a and b). Due to the low carbon and high $\mathrm{Al}$ content of the steel, the hardenability of austenite at temperatures close to $\mathrm{Ac}_{3}$ is extremely low, resulting in the unavoidable formation of ferrite, even at cooling rates greater than $300{ }^{\circ} \mathrm{C} / \mathrm{s}$ (confirmed through dilatometry experiments [14]). Consequently, for this water-quenched specimen, the fine grained ferrite is presumed to be formed on quenching austenite grains formed at temperature and the large ferrite is presumed to be untransformed ferrite consistent with the volume fraction of ferrite and austenite at 970 ${ }^{\circ} \mathrm{C}$ based on dilatometry data. We have assumed that the interface between coarse and fine ferrite grains represents the interface between an untransformed ferrite and austenite grain at high temperatures and that the rapid quench has prevented any $\mathrm{Al}$ re-diffusion. This suggests that the rhomboidal indentation shown in Fig. 1b is located at the interface between an untransformed ferritic region (Grain A in Figs 1(b-d) and $2(\mathrm{a}, \mathrm{b})$ ) and a transformed, former austenitic region (Grain B). A thin foil of this identified boundary region was prepared for TEM by dual beam FIB (Fig. 1c). Electron diffraction confirms that the two grains in the FIB section are ferrite (Fig. 1d and 2a). Atomic lattice imaging of the section revealed a sharp grain boundary interface (Fig. 2b). The spatial distribution of $\mathrm{Al}$ and $\mathrm{Mn}$ respectively across the interface was determined by spot EDX (Figs 3a and b). The areal concentration of Al is significantly higher in grain A (mean $0.94+/-0.06$ wt \% Al) than grain B (mean $0.53+/-0.03$ wt \% Al). The variation in the areal concentrations of $\mathrm{Al}$ and also $\mathrm{Mn}$ could be either due to the fact that the $\mathrm{Al}$ and $\mathrm{Mn}$ distribution is inhomogenous within ferrite or, following the assumptions above, that we are examining 
the dynamic at-temperature transformation interface. If the latter, such a distribution would be expected if partitioning/diffusion of $\mathrm{Al}$ into the untransformed ferrite phase is taking place at high temperature. MTData [20] calculations indicate that the equilibrium Al concentration in both grains should be lower (grain A $0.7 \mathrm{wt} \%$ and grain B $0.48 \mathrm{wt} \%$ ) and may be the case if observed at greater distances from the interface (i.e. in the bulk). The corresponding concentration profile for $\mathrm{Mn}$ is inverse to that for $\mathrm{Al}$ (i.e. it increases from grain $\mathrm{A}$ to $\mathrm{B}$ ) as, in contrast to $\mathrm{Al}, \mathrm{Mn}$ is an austenite stabilizer and so partitions to austenite (Fig. 3b). EDX elemental analysis was also performed across what is presumed to be a former austenite/austenite interface (in the region indicated with an arrow in Fig. 1a) and Fig. 3c shows the areal concentration profile of $\mathrm{Al}$ across this interface. As expected, the results do not show any significant difference in the level of $\mathrm{Al}$ between these two former austenite grains and is similar to the base composition of the steel.

\section{Conclusion}

This investigation shows an increase in $\mathrm{Ac}_{3}$ temperature in the $\mathrm{Al}$ alloyed steel during slow $\left(0.05^{\circ} \mathrm{C} / \mathrm{s}\right)$ heating as compared with fast $\left(7^{\circ} \mathrm{C} / \mathrm{s}\right)$ heating. TEM-EDX analysis of an untransformed ferrite and former austenite interface shows that the rise in $\mathrm{Ac}_{3}$ is due to partitioning of $\mathrm{Al}$ atoms from austenite to the untransformed ferrite, so further stabilizing this phase. In addition, the results show that partitioning of $\mathrm{Mn}$ to austenite takes place during slow heating, consistent with previous studies [2, 3, 16, 17] and is expected because $\mathrm{Mn}$ is a known austenite stabilizer.

\section{Reference:}

[1] San Martin D, De Cock T, Garcia-Junceda A, Caballero F G, Capdevila C, De Andres C G, (2008) Mater Sci and Techn 24:266-72

[2] Garcia C I, Deardo A J, (1981) Metall Trans A 12: 521-30

[3] Speich G R, Demarest V A, Miller R L, (1981) Metall Trans A 12:1419-28

[4] San Martín D, Rivera-Diaz-del-Castillo P E J, (2008) Scripta Mater 58:926-29

[5] García de Andrés C, Caballero F G, Capdevila C, (1998) Scripta Mater 38: 1835-42

[6] Savran V I, Van Leeuwen Y, Hanlon D N, Kwakernaak C, Sloof W G, Sietsma J, (2007) Metall Mater Trans A 38 : 946-55

[7] Luo H, Zhao L, Kruijver S O, Sietsma J, Van der Zwaag S, (2003) ISIJ International 43:1219-27

[8] Sugimoto K, Yu B, Mukai Y, Ikeda S, (2005) ISIJ International 45: 1190-99

[9] De Cooman B C, Curr Opìn (2004) Solid State Mater Sci 82: 85-91

[10] Jiménez-Melero E, Van Dijk N H, Zhao L, Sietsma J, Offerman S E, Wright J P, Van der Zwaag S, (2009) Acta Mater; 57: 533-43

[11] Palizdar Y, Scott A J, Cochrane R C, Brydson R, (2009) Mater Sci and Techn 25: 1243-48

[12] Palizdar Y, Cochrane R C, Brydson R, Crowther D, San Martin D, Scott A J, (2010) Mater Char 61: 159-68 
[13] San Martín D, Palizdar Y, Cochrane R C, Brydson R, Scott A J, (2010) Mater Char 61: 584-88

[14] San Martín D, Palizdar Y, Garcia-Mateo C, Cochrane R C, Brydson R, Scott A J, Metall Mater Trans A, submitted

[15] Caballero F G, Capdevila C, García de Andrés C, (2003) ISIJ International 43: 726-35

[16] Navara E, Bengtsson B, Easterling K E, (1986)Mater Sci Techn 21: 196-01

[17] Lis J, Lis A, Kolan C, (2008) Mater Char 59: 1021-28

[18] Koo J Y, Raghavan M, Thomas G, (1980) Metall Trans A 11: 351-55

[19] Amirthalingam M, Hermans M, Richardson I, (2009) Metall Mater Trans A 40: 901-09

[20] Thermodynamics and phase equilibrium software in: the National Physical Laboratory 
Fig. 1 Micrographs of the microstructure of the heat treated Steel F: a) Back scattered electron image; b) optical metallography image of an interface between a ferritic region and a former austenitic region marked A and B respectively; c) secondary electron image recorded during FIB sectioning of the selected area marked by the rhomboid in b; d) FIB section imaged in the TEM at low magnification, grains A and B are marked.

Fig. 2 a) Bright field TEM image of the untransformed ferrite and former austenite interface identified in Fig. 1, inset are the selected area electron diffraction patterns from the two grains, both index to ferrite in [111] orientation in grain A and [001] orientation in grain B b) TEM lattice image showing that the interface is atomically abrupt

Fig. 3 Elemental concentrations (EDX) of $\mathrm{Al}$ (a) and Mn (b) across the former austenite/ untransformed ferrite interface and $\mathrm{Al}(\mathrm{c})$ across a former austenite/austenite interface. 


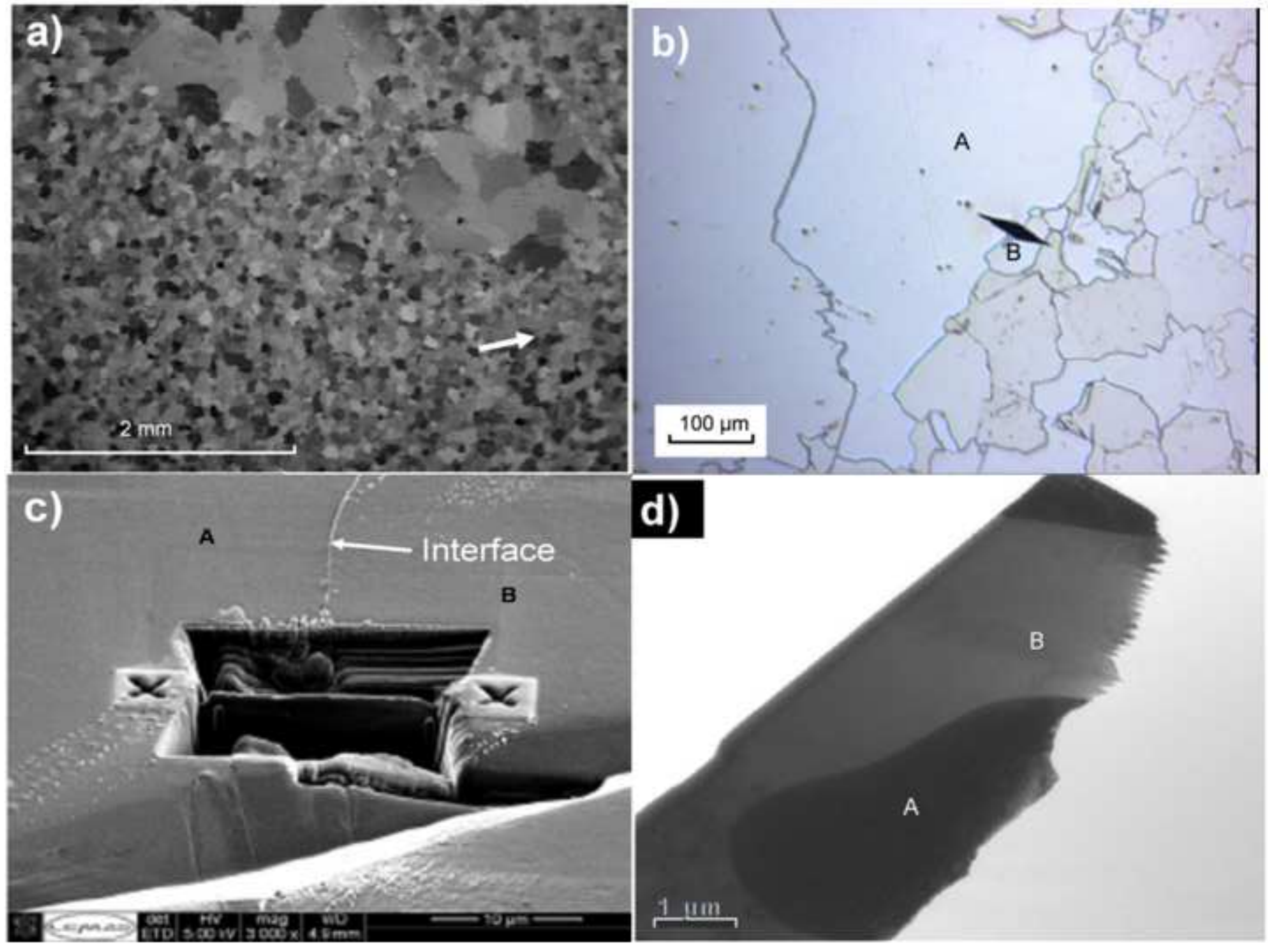




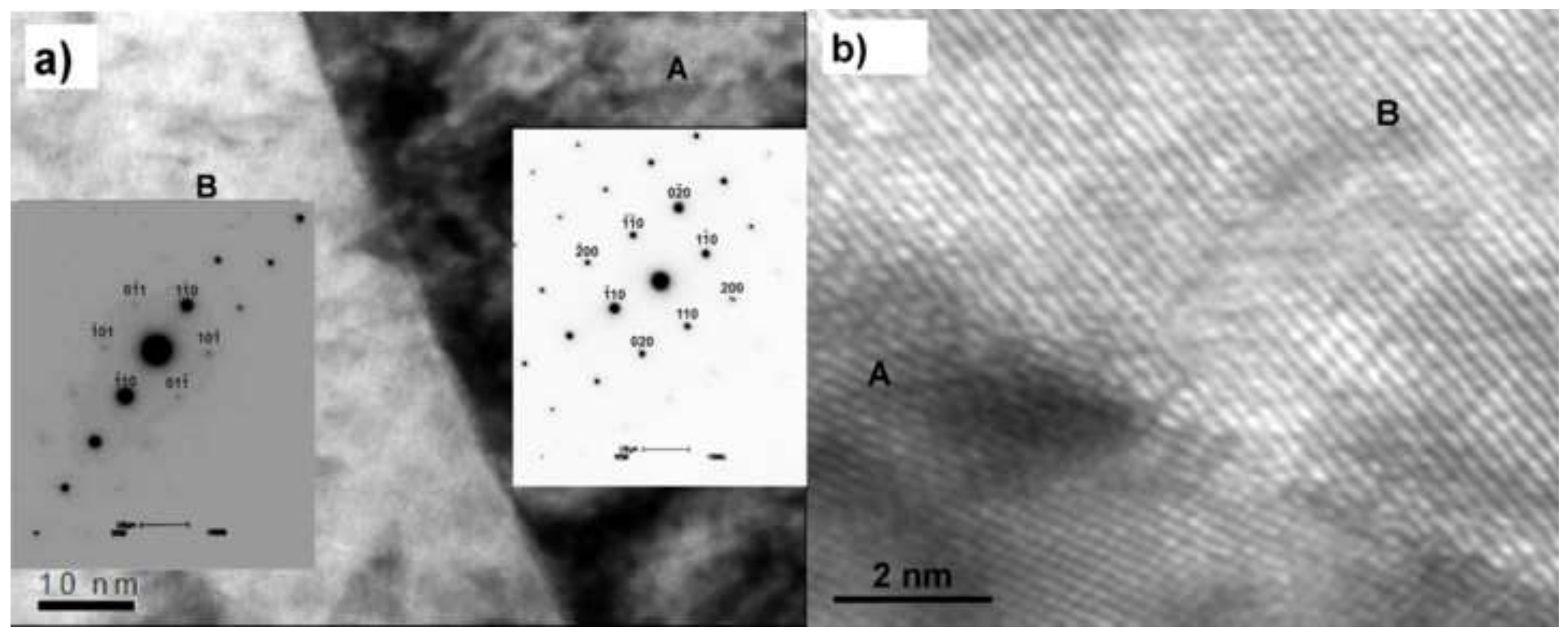




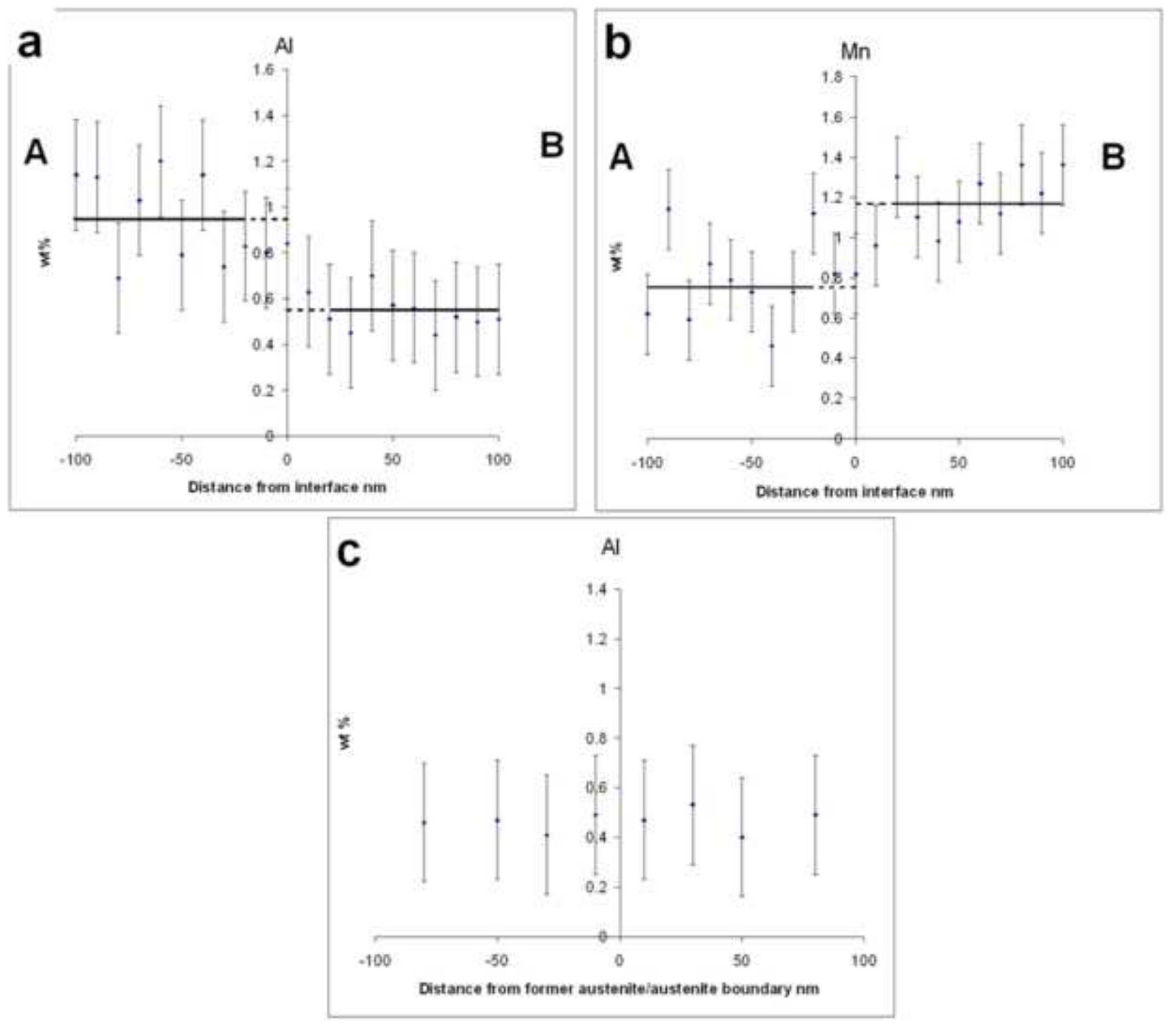


Table 1 Influence of heating rate on temperature $\mathrm{A}_{\mathrm{c} 3}$ for steels $\mathrm{E}(0.02 \mathrm{wt} \% \mathrm{Al})$ and $\mathrm{F}(0.48 \mathrm{wt} \% \mathrm{Al})$

\begin{tabular}{ll}
\hline Heating rate & \\
\hline $0.05{ }^{\circ} \mathrm{C} / \mathrm{s}$ & $7^{\circ} \mathrm{C} / \mathrm{s}$ \\
$910 \pm 7^{\circ} \mathrm{C}$ & $904 \pm 4{ }^{\circ} \mathrm{C}$ \\
$1025 \pm 3{ }^{\circ} \mathrm{C}$ & $987 \pm 2{ }^{\circ} \mathrm{C}$ \\
\end{tabular}

